\title{
The role of past experience in development of feeding behavior in common vampire bats
}

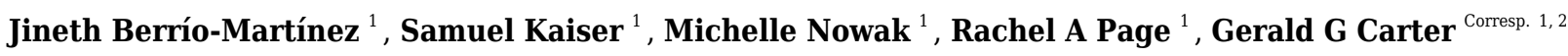 \\ ${ }^{1}$ Smithsonian Tropical Research Institute, Balboa, Ancón, Panama \\ 2 Department of Evolution, Ecology and Organismal Biology, The Ohio State University, Columbus, Ohio, United States \\ Corresponding Author: Gerald G Carter \\ Email address: carter.1640@osu.edu
}

The life history strategy of common vampire bats (Desmodus rotundus) suggests that learning might play a role in development of their foraging skills. We took advantage of 12 captive births in a study colony of vampire bats to test the role of past experience in two aspects of feeding. First, we compared preferences for blood temperature in 32 wild-born vampire bats versus 11 captive-born vampire bats that had only previously fed on blood of ambient temperature or colder. We found no evidence for a preference in either group for blood presented at $4{ }^{\circ} \mathrm{C}$ versus $37^{\circ} \mathrm{C}$. Second, we tested whether captive-born vampire bats with no previous experience of feeding on live animals could successfully feed on a live chicken. Five of 12 naïve captive-born bats were able to bite the chicken and draw blood, but only one bat gained more than $5 \%$ of body mass. We were unable to reasonably compare their feeding performance with that of wild-born bats because only two of three wild-born, short-term captive bats fed on the chicken and none of the seven wild-born, long-term captive mothers attempted to feed. This unexpected lack of feeding might be due to a previously reported age-dependent neophobia. When six of the captive-born bats were released in the wild, they appeared to feed successfully because they survived for more than three consecutive nights. We suggest further tests that would better clarify the role of learning in the development of foraging in vampire bats. 


\section{THE ROLE OF PAST EXPERIENCE IN DEVELOPMENT}

\section{OF FEEDING BEHAVIOR IN COMMON VAMPIRE BATS}

5 Jineth Berrío-Martínez ${ }^{1}$, Samuel Kaiser ${ }^{1}$, Michelle Nowak ${ }^{1}$, Rachel A. Page ${ }^{1}$, Gerald G. Carter ${ }^{1,2}$

$7 \quad{ }^{1}$ Smithsonian Tropical Research Institute, Balboa, Ancón, Panamá

$8{ }^{2}$ Department of Evolution, Ecology and Organismal Biology, The Ohio State University, USA

10 Corresponding Author:

11 Gerald G. Carter

12318 W 12th Ave, Columbus, OH, 43210, USA

13 Email address: carter.1640@osu.edu

\section{ABSTRACT}

The life history strategy of common vampire bats (Desmodus rotundus) suggests that learning

17 might play a role in development of their foraging skills. We took advantage of 12 captive births

18 in a study colony of vampire bats to test the role of past experience in two aspects of feeding.

19 First, we compared preferences for blood temperature in 32 wild-born vampire bats versus 11

20 captive-born vampire bats that had only previously fed on blood of ambient temperature or

21 colder. We found no evidence for a preference in either group for blood presented at $4{ }^{\circ} \mathrm{C}$ versus 
$2237^{\circ} \mathrm{C}$. Second, we tested whether captive-born vampire bats with no previous experience of

23 feeding on live animals could successfully feed on a live chicken. Five of 12 naïve captive-born

24 bats were able to bite the chicken and draw blood, but only one bat gained more than $5 \%$ of body

25 mass. We were unable to reasonably compare their feeding performance with that of wild-born

26 bats because only two of three wild-born, short-term captive bats fed on the chicken and none of

27 the seven wild-born, long-term captive mothers attempted to feed. This unexpected lack of

28 feeding might be due to a previously reported age-dependent neophobia. When six of the

29 captive-born bats were released in the wild, they appeared to feed successfully because they

30 survived for more than three consecutive nights. We suggest further tests that would better

31 clarify the role of learning in the development of foraging in vampire bats.

\section{INTRODUCTION}

33 Common vampire bats, Desmodus rotundus (E. Geoffroy, 1810), possess a suite of traits

34 associated with complex foraging skills that are learned gradually over time (Schuppli, Isler \&

35 van Schaik, 2012). These traits include flexible foraging, slow development, individualized

36 social relationships, extended parental care, and sharing of food with nonkin (Schuppli, Isler \&

37 van Schaik, 2012). Vampire bats are arguably flexible foragers because they rely on a

38 combination of vision, echolocation, passive listening, olfaction, mechanoreception, and

39 thermoperception to extract blood from a diverse range of vertebrate hosts (Greenhall, 1988;

40 Schmidt et al., 1991; Gröger \& Wiegrebe, 2006). They have a long lifespan, with records of 29

41 years in captivity (GGC, personal observation) and at least 17 years in the wild (Delpietro et al.,

42 2017), and are an outlier among bats with regards to their maternal investment and slow

43 reproduction. Gestation requires 5.5 to 7.3 months, and sexual maturity requires up to 9.5 months

44 (Schmidt, 1988; Delpietro \& Russo, 2002). Juveniles are born large (roughly a quarter of the 
45 mother's mass) and depend on their mother for longer than any other bat species; mothers nurse

46 juveniles for 8 to 10 months. In contrast, lactation periods in temperate and other neotropical bats

47 are typically 3 weeks to 3 months (Jenness \& Studier, 1976; Kunz \& Robson, 1995; Hamilton \&

48 Barclay, 1998; Crichton \& Krutzsch, 2000; Delpietro \& Russo, 2002; Kwiecinski, Falzone \&

49 Studier, 2003; Chaverri \& Kunz, 2006). Female vampire bats form long-term social relationships

50 that involve regurgitations of blood to unfed individuals in need (Wilkinson, 1984, 1985;

51 Delpietro \& Russo, 2002; Carter \& Wilkinson, 2013; Delpietro et al., 2017). This cooperative

52 social support is especially important for younger bats because vampire bats will die after three

53 consecutive unfed nights and individuals younger than two years fail to feed on roughly one-

54 third of nights (Wilkinson, 1984). Vampire bats have one of the largest brain and neocortical

55 volumes for their body size among bats (Baron, Stephan \& Frahm, 1996; Bhatnagar, 2008).

56 Finally, young vampire bats show increased exploration and decreased neophobia that peaks at

57 9-10 months (Park, 1990; Vrtilek et al., 2018). This unique combination of social complexity,

58 slow life history, and flexible foraging make vampire bats a good candidate for a large role for

59 learning in foraging. On the other hand, vampire bats are obligate blood-feeders and this extreme

60 dietary specialization can also lead to evolutionary losses in learning ability. For instance,

61 vampire bats have lost the widespread adaptive specialization of taste aversion learning

62 (Ratcliffe, Fenton \& Galef, 2003).

63

64 How important is learning during development of feeding behavior in vampire bats? To begin to

65 answer this question, we took advantage of an existing captive colony of both captive-born and

66 wild-born bats to test the role of past experience in feeding behavior. In the first test, we asked

67 whether captive-born vampire bats show an innate preference for warm blood. Vampire bats 
68 possess unique heat receptors near their nostrils which allow them to detect blood-rich areas on

69 the skin of their hosts at distances of up to $16 \mathrm{~cm}$ (Kürten \& Schmidt, 1982; Schmidt \& Manske,

70 1982). One previous study found that wild vampire bats will consume blood as cold as $14{ }^{\circ} \mathrm{C}$

71 (Bullard \& Shumake, 1973), but the role of past experience in blood-temperature perception and

72 preference remains ambiguous. We compared the blood-temperature preferences of wild-born

73 bats with captive-born bats that had previously only fed on chilled or ambient temperature blood.

74 If learning plays a key role in their use of thermoperception, then we expected that captive-born

75 vampire bats would differ from wild-born bats. Specifically, wild-born bats should show a

76 greater preference for warmer blood $\left(37^{\circ} \mathrm{C}\right)$ over artificially chilled blood $\left(4^{\circ} \mathrm{C}\right)$.

78 In the second test, we asked whether captive-born vampire bats could successfully feed from a

79 live animal, given their complete lack of experience with this task. If a critical period of early

80 experience or social learning is required for extracting blood from a live animal, then naïve

81 captive-born bats, reared without experiencing feeding on live host animals, might be unable to

82 feed successfully on live hosts. In the wild, younger vampire bats have been observed feeding

83 from the same wound as their mothers (Wilkinson, 1985). Therefore, to test for whether the

84 presence of mothers helps their offspring learn how to feed, we tested naïve captive-born bats

85 alone and again in the presence of their wild-born mothers.

86

87 MATERIALS \& METHODS

88 Animal subjects

89 As test subjects, we used 12 captive-born common vampire bats (Desmodus rotundus, 6 females,

906 males) and 24 wild-born long-term captive females. Additionally, we tested eight adult 
91 common vampire bats that were recently captured from the wild near Rio Indio, Chilibre in

92 Chagres National Park, Panamá. Bats were housed at the Smithsonian Tropical Research

93 Institute (STRI) in Gamboa, Panamá. Experiments were conducted from June to August 2017.

94 We tested captive-born subjects aged from 6 to 16 months, which is after the period when

95 captive young vampire bats begin feeding on blood on their own (Schmidt, 1988b). The long-

96 term captive bats had fed on live animals before being captured in either December 2015 or June

97 2016. In captivity, they were fed with bovine or pig blood that was about $4{ }^{\circ} \mathrm{C}$ when first

98 presented and that rose to ambient temperature (roughly $30^{\circ} \mathrm{C}$ ) during the night. The recently

99 captured wild bats had no past experience with blood colder than the body temperature of their

100 host. In contrast, the captive-born bats had no past experience with live prey or blood that was

101 warmer than ambient temperature.

102

103 Research was approved by the STRI Animal Care and Use Committee (\#2015-0915-2018-A9)

104 and by the Panamanian Ministry of the Environment (\#SE/A-76-16) and adhered to the standards

105 of the American Society of Mammalogists Guidelines for use and handling of wildlife mammals

106 for research (Sikes \& The Animal Care and Use Committee of the American Society of

107 Mammalogists, 2016).

108

109 Experiment 1: Do captive-born vampire bats prefer warm blood?

\section{Experimental procedure}

111 We presented an unfed individual vampire bat in a $28 \times 28 \times 40 \mathrm{~cm}$ acrylic and mesh cage with

112 two adjacent feeders, one filled with warm blood $\left(37^{\circ} \mathrm{C}\right)$ and the other filled with cold blood (4

$113^{\circ} \mathrm{C}$ ). Each silo-style feeder was designed to provide water to birds and had one spout. We 
114 modified the feeders by insulating the tubes with polystyrene foam. The two spouts were

115 positioned about $5 \mathrm{~cm}$ apart and were filled from the reservoir tubes of blood $(\sim 20 \mathrm{ml})$. Cold

116 blood was chilled in a refrigerator until the trial began and warm blood was warmed in a hot-

117 water bath (Polyscience Waterbath, Niles, Illinois). Each feeder was then immediately placed

118 into polystyrene foam insulators designed to maintain the temperature of the blood. The

119 placement of feeders on the left or right was alternated for each trial. Trials lasted about one hour

$120($ mean $=62 \mathrm{~min}$, range $=52$ to $74 \mathrm{~min})$, except for two interrupted trials that were 25 and 32

121 minutes respectively. We confirmed that the warmer blood always remained warmer during

122 trials, by taking five measures of feeder-blood temperature over time. After one hour, the mean

123 temperature of the insulated blood only changed by $5^{\circ} \mathrm{C}$, and the bats chose a feeder within the

124 first 15 min in most trials (70\%), with a median latency to choose of 2.8 min. Blood temperatures

125 were therefore very different when bats chose a feeder.

126

127 We used an infrared surveillance camera to record the bat's behavior and measure the amount of

128 time a bat spent drinking from each blood spout. As a response variable, we defined feeding time

129 bias as the difference in the proportion of time spent feeding on warm blood versus cold blood

130 (e.g. 1.0 for $100 \%$ warm blood; 0 for $50 \%$ warm blood, and -1.0 for $100 \%$ cold blood). We

131 initially measured the mass change in the two feeders by weighing the feeders immediately

132 before and after the trial, but we found that this measure was inaccurate due to condensation

133 forming on the colder tube, and a small amount of blood spilling due to the expansion of the

134 colder air in the tube. For the best measure of consumption, we therefore used seconds of

135 drinking time, which predicted the change in feeder weight (Pearson's $r=0.77, \mathrm{df}=-128, \mathrm{p}<$

136 0.0002). We also scored the bat's first choice and the number of feeding events for each spout, 
137 where a feeding event is defined as the bat putting its mouth into the spout. Our conclusions do

138 not differ when we instead compared differences in feeder weight or number of feeding events.

140 We tested 11 captive-born vampire bats and 24 long-term captive bats twice and tested the eight

141 wild bats three or four times. We took the mean feeding time bias for each bat as our

142 observational unit. To infer whether mean feeding time biases differed from zero, we used

143 bootstrapping with 5000 samples (Canty \& Ripley, 2015) to calculate the $95 \%$ confidence

144 interval of the mean feeding time bias. These confidence intervals are a better alternative to post

145 hoc power analysis for interpreting null results (Levine \& Ensom, 2001).

146

147 Experiment 2: Can captive-born vampire bats feed on live prey?

148 Experimental procedure

149 For test subjects, we used 12 captive-born vampire bats described above, seven of their wild-

150 born mothers, and three recently wild-captured adults. For live prey, we used 15 adult hens,

151 Gallus gallus, because they are easy to handle and maintain, they pose little threat to the bats,

152 and studies show that wild common vampire bats will readily feed on live chickens in proportion

153 to their availability (e.g. Greenhall, Schmidt \& Lopez-Forment, 1971; Greenhall, 1972;

154 Bobrowiec, Lemes \& Gribel, 2015). Hens were individually marked with colored leg bands, such

155 that no hen was fed on more than once every 20 days. Hen health was carefully monitored

156 throughout the experiment. All hens remained healthy and active throughout the experiment. We

157 saw no evidence of long-term repercussions from the bat feedings.

158 
159 In each trial, we presented one hen to an unfed captive-born vampire bat in an experimental

160 arena and left them undisturbed until sunrise. The experimental arena was $50 \times 50 \times 69 \mathrm{~cm}$ with

161 three glass sides, and a mesh side and ceiling. Trials started between 2319 and 2346 hours,

162 except for one trial that started at $0059 \mathrm{~h}$. During this time, we used an infrared surveillance

163 camera system to record video from multiple angles. For the chicken, we provided a wooden

164 perch elevated about $4 \mathrm{~cm}$ from the floor and a water dish. We used a fan to ventilate the

165 experimental arena and to help maintain an ambient temperature. As a refuge for the vampire

166 bat, we attached a mesh plastic tube covered with black plastic to a top corner of the arena. We

167 weighed all vampire bat subjects before and after each trial. Before releasing the chicken the next

168 morning, we photographed any bites on the chicken. The arena was cleaned between trials. We

169 used the video recordings to score interactions among vampire bats and chickens, including:

170 latency until feeding, duration of feeding events, number of attempted bites before a successful

171 feeding, and duration of time spent moving around outside the refuge.

172

173 To test whether the presence of mothers would increase the feeding success of their young, we

174 also tested five female and one male captive-born bats simultaneously with their mother, which

175 were captured from the wild (near Tolé or Las Pavas, Panamá) then housed in captivity for one

176 to four months. We did not test reproductively mature sons with their mothers to avoid possible

177 mating attempts and fighting. Trials with and without the presence of mothers were conducted in 178 random order.

179

180 To compare with data from the captive-born bats, we also conducted six control trials with wild-

181 born bats. In the first three control trials, we tested an adult long-term captive mother alone. In 
182 the next three control trials, we individually tested two females and one male that were recently

183 captured from the wild.

184

\section{RESULTS}

\section{Experiment 1. Do captive-born vampire bats prefer warmer blood?}

187 We did not detect a blood temperature preference in captive-born or wild-born vampire bats

188 (Figure 1, Data S1). The bats appeared to detect both spouts, choose independently of their

189 temperature, and simply consume more blood from whichever spout they chose first (Fisher's

190 exact test; odds ratio $=26, \mathrm{n}=41, \mathrm{p}<0.0001)$. The first choice of spout explained $62 \%$ of the

191 variation in the feeding time bias, and the subject drank from only one spout in $71 \%$ of 135 trials.

192

\section{Experiment 2. Can captive-born vampire bats feed on live prey?}

194 We found that captive-born vampire bats could successfully bite a live chicken without previous

195 experience or maternal assistance. Their feeding success, however, was ambiguous. Five of the

19612 captive-born bats bit the chicken when tested alone, and one of the six captive-born bats bit in

197 the presence of their mother (Table 1, Video S1), yet four of the five captive-born bats that fed

198 did not gain more than $1 \mathrm{~g}$ of mass, showing that their feeding performance was poor (Table 2,

199 Data S2). The oldest captive-born vampire bat (16 months old) fed on live prey to an extent that

200 was comparable to the wild-born adults, and it gained a 12\% increase in body mass (Table 2),

201 but the other four captive-born bats that were capable of making a wound and feeding from it,

202 did not gain much weight (-3\% to $+3 \%$ change in body mass).

203

204 DISCUSSION 
205 Neither the captive-born nor wild-born vampire bats preferred warmer blood. Wild vampire bats

206 will feed from wounds created by other vampire bats, so it is not too surprising that they readily

207 drink from an open spout of blood (Greenhall, Schmidt \& Lopez-Forment, 1971; Wilkinson,

208 1985). It is more surprising, however, that their reliance on thermoperception did appear to not

209 generalize to this novel situation. Vampire bats rely on thermoperception to find blood vessels

210 near the surface of the skin, and will choose to bite the warmer of two rabbit ears (Kürten \&

211 Schmidt, 1982; Schmidt \& Manske, 1982). Yet a previous study reported that, when eight wild

212 vampire bats were presented with choices of blood at $14{ }^{\circ} \mathrm{C}, 30^{\circ} \mathrm{C}, 38.5^{\circ} \mathrm{C}$, and $47^{\circ} \mathrm{C}$, the bats

213 did not show a temperature bias except for an avoidance of the $47^{\circ} \mathrm{C}$ blood, possibly due to the

214 denaturing of the blood proteins (Bullard \& Shumake, 1973). Our study repeated this test using a

215 more statistically powerful approach: we tested more subjects with a choice between two

216 temperatures that were more different from each other. Our results corroborated the past findings

217 and show that wild-born vampire bats will feed on blood as cold as $5{ }^{\circ} \mathrm{C}$, even in the presence of

218 blood at a more natural warm temperature. Clearly, heat is not the only cue that vampire bats use

219 to select a blood source. The subjects presumably detected and chose spouts using other

220 modalities such as olfaction and echolocation, and thermoperception is thus only one aspect of a

221 vampire bat's multimodal assessment of a bite site or blood source.

222

223 Captive-born vampire bats could feed on a live animal (Table 1), but it is difficult to interpret

224 their feeding performance (Table 2). Rapid urination causes large changes in body mass that can

225 complicate the measurement of blood consumption in vampire bats (Wimsatt \& Guerriere,

226 1962). Nevertheless, the bats in this test appeared to feed less than expected under typical

227 circumstances. Even when only considering the bats that did gain mass, the average gain $(\sim 3 \mathrm{~g}$, 
228 Table 2) was still less than half of the mass gains observed in the wild ( $\sim 6 \mathrm{~g}$, Turner, 1975) or in

229 captivity ( $\sim 9$ g, Breidenstein, 1982).

230

231 Two of the three wild-born, short-term captive vampire bats fed on the chicken successfully

232 (Table 2). Unexpectedly, the adult long-term captive mothers did not feed on the chicken at all,

233 either when tested alone (three trials), or with their daughter (six trials). We also never observed

234 the adults feeding on the chicken in six pilot trials with alternative experimental setups. There are

235 several possible explanations for why none of the mothers fed nor even seemed motivated to

236 feed. Older captive bats may have been less motivated to feed due to differences in metabolic

237 demands, but this seems unlikely given the susceptibility of vampire bats to fasting (Wilkinson,

238 1984; Freitas et al., 2013). The adult bats had been fasted in trials for another experiment to

239 induce food sharing (following Carter \& Wilkinson, 2013), so they might have habituated or

240 learned that they would eventually be released back into the main cage due to their experiences

241 of being repeatedly isolated overnight without food. However, the captive-born bats had similar

242 experiences.

243

244 Perhaps the most likely explanation is that adult vampire bats are more neophobic and less

245 exploratory than younger vampire bats. A previous study showed that the same captive-born bats

246 were an order of magnitude more likely to explore a novel object compared to their adult

247 groupmates (Carter et al., 2018). In the feeding trials of this study, the younger captive-born bats

248 in the experimental arena were more active than the adults with regards to jumping, walking,

249 sniffing, and interacting with the chickens (mean hours of activity for adults $=5.1 \mathrm{~h}, 95 \% \mathrm{CI}=$

2504.1 to $6.3 \mathrm{~h}, \mathrm{n}=10$; for young captive-born bats $=7.2 \mathrm{~h} ; 95 \% \mathrm{CI}=6.9$ to $7.5 \mathrm{~h}, \mathrm{n}=12$; Video 
251 S2). When tested alone, all 12 captive-born young explored the floor of the experimental area,

252 whereas only one of three mothers did. When tested in mother-daughter pairs, five of the six

253 captive-born daughters and three of the six wild-born mothers moved to the floor. Most of the

254 captive-born bats left the refuge a few minutes after the experimenter left, whereas most of the

255 adult bats did not explore the floor of the test cage at all during the whole night. When tested

256 with her daughter, one of the mothers did not even leave the refuge the entire night. These

257 observations are consistent with past tests showing age-dependent exploration or neophobia

258 (Carter et al., 2018).

259

260 An anecdotal observation of age-dependent boldness in a novel feeding context comes from a

261 different captive colony (described in Carter \& Wilkinson, 2013). In this colony, one of the

262 authors (GGC) noticed that several of the ten captive-born younger bats would often fly and land

263 on the author when he entered the flight cage, sometimes climbing along his back or up and

264 down his legs. When he held still, one vampire bat attempted to bite his ear. The same behavior

265 was reported by another animal caretaker. In sharp contrast, none of the 22 older adult captive-

266 born bats in the group approached or landed on people entering the flight cage, and they instead

267 typically flew away to a corner or remained vigilant and motionless.

269 Despite the apparent difference in performance, the actual biting behavior of captive-born bats

270 was generally consistent with the wild-born, short-term captive adults, and with past descriptions

271 of feeding behaviors where individuals took anywhere from a few minutes to $40 \mathrm{~min}$ to bite an

272 animal (Greenhall, Schmidt \& Lopez-Forment, 1971; Greenhall, 1972, 1988). The chickens were

273 only bitten on the digits, ankle, and areas near the tail that lacked feathers. This is consistent with 
274 observations that vampire bats readily target unprotected areas of skin (Greenhall, 1988). To test

275 for more subtle differences in feeding performance, one needs a larger behavioral sample from

276 captive-born and wild-born bats tested under controlled conditions.

277

278 In conclusion, naïve young without any relevant past experience can feed on live prey, but it

279 remains unclear how the feeding development and performance of captive-reared vampire bats

280 compares with more experienced wild-reared adults. Our results suggest that social learning from

281 mothers plays at most a supplementary role in the acquisition of the flexible extractive foraging

282 skills of vampire bats.

283

\section{CONCLUSIONS}

285 In this study, we took advantage of a long-term captive colony to test some ideas about the

286 development of feeding behaviors in captive-born bats. We had two unexpected results. First, we

287 observed no temperature preference for blood in either captive-born, long-term captive, or

288 recently wild-capture vampire bats. When vampire bats fed from spouts, they did not generalize

289 their thermal preferences for bite sites on live animals. Thermal cues used during normal feeding

290 are therefore not used in every feeding context. Future studies could incorporate trials where

291 both captive-born and wild-born vampire bats are presented with bite sites on live animals that

292 vary in temperature or other traits (following Schmidt \& Manske, 1982).

293

294 Second, naïve captive-born common vampire bats can feed on live prey. Further studies could

295 test how lack of experience influences feeding performance. One possible improvement to our 
296 study design would be to fully habituate all subjects to the feeding arena, by allowing isolated

297 bats to feed from a dish of blood in the arena over several nights, before presenting a live animal. 298

299 The role of learning in other bat species and mammals is not easy to predict. For example, frog-

300 eating bats (Trachops cirrhosus) feed by eavesdropping on the mating calls of several prey

301 species, such as katydids and frogs, some of which are toxic (Page \& Jones, 2016). These bats

302 possess traits that suggest adaptation for hunting frogs, such as increased innervation in the part

303 of the cochlea that allows for low-frequency hearing, allowing them to hear in the range of frog

304 advertisement calls (Bruns, Burda \& Ryan 1989). Under such conditions, where predators have

305 adaptations for specific kinds of prey and mistakes are costly, one would expect that preferences

306 for specific frog calls would be fixed. More than a decade of work, however, shows the opposite

307 trend: frog-eating bats are highly flexible, with the ability to learn both asocially and socially,

308 rapidly acquiring and reversing associations between calls and prey quality (Page \& Ryan, 2005,

309 2006; Jones et al., 2013; Patriquin et al., 2018). In contrast, other studies show that bats also

310 possess largely innate heuristics under unexpected conditions. For example, naïve captive-born

311 insectivorous bats treat any sufficiently large horizontal smooth surface as water, even a surface

312 that they can fly beneath (Greif \& Siemers, 2010). Naïve captive-born flower-visiting

313 Glossophaga bats are strongly and innately attracted to dimethyl disulfide, a component of many

314 neotropical bat-pollinated flowers (Helversen, Winkler \& Bestmann, 2000; Carter, Ratcliffe \&

315 Galef, 2010). Yet, the performance of these bats when learning simple cue-based associations

316 and generalizing them to new environments is surprisingly bad (Stich \& Winter, 2006), and this

317 is because both innate preferences for dimethyl disulfide and learned preferences for novel cues 
318 can be overshadowed by spatial memory (Thiele \& Winter, 2005; Stich \& Winter, 2006; Carter,

319 Ratcliffe \& Galef, 2010).

320

321 Another purpose of this study was to assess whether captive-born vampire bats would be likely

322 to survive after being released into the wild. Captive-born animals are typically less likely to

323 survive than wild-caught individuals (Stoinski et al., 2003), but there is much variation between

324 species and studies (e.g. Stoinski et al., 2003; Piep et al., 2008; Benson-Amram et al., 2014;

325 Rogers et al., 2016; Abu Baker et al., 2018; Yang et al., 2018). Very little is known about how

326 well captive-reared bats can acquire the necessary skills for foraging in the wild (Courts, 1997;

327 Constantine, 2003; Ruffell \& Parsons, 2009; Serangeli et al., 2012). Some insectivorous bat

328 species can apparently go from captive hand-feeding to successful wild foraging, whereas others

329 must first learn how to forage on flying insects in a flight cage (Kelly et al., 2008, 2012;

330 Serangeli et al., 2012). Captive-reared animals develop a smaller hippocampus (LaDage et al.,

331 2009; Tarr et al., 2009), and are likely to be cognitively and physiologically different in other

332 ways. Six of the captive-born vampire bats from this study were released back into the wild and

333 observed visually and tracked with automated proximity loggers (Ripperger et al., 2016, 2018; in

334 prep) until they left the site. We confirmed that all these bats survived for at least three days in

335 the wild and four of the six survived for at least 5 or 6 days, before departing the site. We

336 observed no deaths. These observations suggest that the captive-born bats were also capable of

337 feeding on wild prey.

338

339 ACKNOWLEDGMENTS 
340 We thank Ahana Aurora Fernandez, Sebastian Stockmaier, Darija Josic, Vanessa Pérez, and May

341 Dixon for help with care of chickens. We thank the Smithsonian Tropical Research Institute for

342 logistical support and staff of the Ministry of Agricultural Development (MIDA) in Colón,

343 Panamá, especially Rogelio Singh, for help with catching the wild vampire bats.

344

\section{REFERENCES}

346 Abu Baker MA, Villamil LA, Reeve N, Karanassos C, Mahtab H, Yamaguchi N. 2018. Into the

347 wild: Survival, movement patterns, and weight changes in captive Ethiopian hedgehogs,

348 Paraechinus aethiopicus following their release. Journal of Arid Environments 158:43-56.

349 DOI: $10.1016 /$ j.jaridenv.2018.05.009.

350 Baron G, Stephan H, Frahm HD. 1996. Comparative Neurobiology in Chiroptera. Basel, Boston, $351 \quad$ Berlin: Birkhäuser Verlag.

352 Benson-Amram S, Heinen VK, Gessner A, Weldele ML, Holekamp KE. 2014. Limited social 353 learning of a novel technical problem by spotted hyenas. Behavioural Processes 109:111120. DOI: 10.1016/j.beproc.2014.09.019.

Bhatnagar KP. 2008. The brain of the common vampire bat, Desmodus rotundus murinus

(Wagner, 1840): a cytoarchitectural atlas. Brazilian Journal of Biology 68:583-599.

Bobrowiec PED, Lemes MR, Gribel R. 2015. Prey preference of the common vampire bat (Desmodus rotundus, Chiroptera) using molecular analysis. Journal of Mammalogy 96:5463. DOI: 10.1093/jmammal/gyu002.

Breidenstein CP. 1982. Digestion and assimilation of bovine blood by a vampire bat (Desmodus rotundus). Journal of Mammalogy 63:482-484.

362 Bullard RW, Shumake SA. 1973. Food temperature preference response of Desmodus rotundus. 
Journal of Mammalogy 54:299-302.

364 Bruns V, Burda H, Ryan MJ. 1989. Ear morphology of the frog-eating bat (Trachops cirrhosus,

365 Family: Phyllostomidae): apparent specializations for low-frequency hearing. Journal of 366 Morphology 199:103-118.

367 Canty A, Ripley B. 2015.boot: Bootstrap R (S-Plus) Functions

368 Carter GG, Forss S, Page RA, Ratcliffe JM. 2018. Younger vampire bats (Desmodus rotundus)

369 are more likely than adults to explore novel objects. PLoS ONE 13:e0196889. DOI:

$370 \quad$ 10.1371/journal.pone.0196889.

371 Carter GG, Ratcliffe JM, Galef BG. 2010. Flower bats (Glossophaga soricina) and fruit bats

372 (Carollia perspicillata) rely on spatial cues over shapes and scents when relocating food.

$373 \quad$ PloS ONE 5:e10808. DOI: 10.1371/journal.pone.0010808.

374 Carter GG, Wilkinson GS. 2013. Food sharing in vampire bats: Reciprocal help predicts

375 donations more than relatedness or harassment. Proceedings of the Royal Society B 280:1-

376 6. DOI: $10.1098 /$ rspb.2012.2573.

377 Chaverri G, Kunz TH. 2006. Reproductive biology and postnatal development in the tent-making

378 bat Artibeus watsoni (Chiroptera: Phyllostomidae). Journal of Zoology 270:650-656. DOI:

$379 \quad 10.1111 / \mathrm{j} .1469-7998.2006 .00171 . x$.

380 Constantine DG. 2003. Geographic translocation of bats: Known and potential problems.

381 Emerging Infectious Diseases 9:17-21. DOI: 10.3201/eid0901.020104.

382 Courts S. 1997. Insectivory in captive Livingstone's and Rodrigues fruit bats (Pteropus

383 livingstonii) and (P. rodricensis) (Chiroptera: Pteropodidae): A behavioural adaptation for

384 obtaining protein. Journal of Zoology 242:404-410. DOI: 10.1111/j.1469-

$385 \quad$ 7998.1997.tb05815.x. 
386 Crichton EG, Krutzsch PH. 2000. Reproductive Biology of Bats. New York: Academic Press.

387 Delpietro HA, Russo RG. 2002. Observations of the common vampire bat (Desmodus rotundus)

388 and the hairy-legged vampire bat (Diphylla ecaudata) in captivity. Mammalian Biology

389 67:65-78. DOI: $10.1078 / 1616-5047-00011$.

390 Delpietro HA, Russo RG, Carter GG, Lord RD, Delpietro GL. 2017. Reproductive seasonality,

391 sex ratio, and philopatry in Argentina's common vampire bats. Royal Society Open Science

392 4:1-14. DOI: 10.1098/rsos.160959.

393 Freitas MB, Queiroz JF, Dias Gomes CI, Collares-Buzato CB, Barbosa HC, Boschero AC,

394 Gonçalves CA, Pinheiro EC. 2013. Reduced insulin secretion and glucose intolerance are

395 involved in the fasting susceptibility of common vampire bats. General and Comparative

396 Endocrinology 183:1-6. DOI: 10.1016/j.ygcen.2012.11.023.

397 Greenhall A. 1972. The biting and feeding habits of the vampire bat, Desmodus rotundus.

398 Journal of Zoology 168:451-461.

399 Greenhall A. 1988. Feeding Behavior. In: Greenhall A, Schmidt U, eds. Natural history of

$400 \quad$ vampire bats. Florida: CRC Press, 111-131.

401 Greenhall AM, Schmidt U, Lopez-Forment W. 1971. Attacking behavior of the vampire bats,

402 Desmodus rotundus, under field conditions in Mexico. Biotropica 3:136-141.

403 Greif S, Siemers BM. 2010. Innate recognition of water bodies in echolocating bats. Nature

404 Communications 1:1-5. DOI: 10.1038/ncomms1110.

405 Gröger U, Wiegrebe L. 2006. Classification of human breathing sounds by common vampire bat, 406 Desmodus rotundus. BMC Biology 4:1-8. DOI: 10.1186/1741-7007-4-18.

407 Hamilton IM, Barclay RMR. 1998. Ontogenetic influences on foraging and mass accumulation 408 by bats big brown (Eptesicus fuscus). Journal of Animal Ecology 67:930-940. 
409 Helversen O von, Winkler L, Bestmann HJ. 2000. Sulphur-containing "perfumes” attract flower-

$410 \quad$ visiting bats. Journal of Comparative Physiology A 186:143-153. DOI:

$411 \quad 10.1183 / 20734735.007714$.

412 Jenness R, Studier EH. 1976. Lactation and milk. In: Baker RJ, Jones KJ Jr., Carter DC, eds.

413 Biology of Bats of the New World Family Phyllostomatidae. Part I. Lubbock: Special

414 Publications of the Museum, Texas Tech University, 201-2018.

415 Jones PL, Ryan MJ, Flores V, Page RA. 2013. When to approach novel prey cues? Social

416 learning strategies in frog-eating bats. Proceedings of the Royal Society B 280:1-6. DOI:

$417 \quad 10.1098 / \mathrm{rspb} .2013 .2330$.

418 Kelly A, Goodwin S, Grogan A, Mathews F. 2008. Post-release survival of hand-reared

419 pipistrelle bats (Pipistrellus spp). Animal Welfare 17:375-382.

420 Kelly A, Goodwin S, Grogan A, Mathews F. 2012. Further evidence for post-release survival of 421 hand-reared, orphaned bats based on radio-tracking and ring return data. Animal Welfare $422 \quad 21: 27-31$.

423 Kunz TH, Robson SK. 1995. Postnatal growth and development in the mexican free-tailed bat 424 (Tadarida brasiliensis mexicana): birth size, growth rates, and age astimation. Journal of Mammalogy 76:769-783. DOI: 10.2307/1382746.

426 Kürten L, Schmidt U. 1982. Thermoperception in the common vampire bat (Desmodus 427 rotundus). Journal of Comparative Physiology A 146:223-228.

428 Kwiecinski GG, Falzone M, Studier EH. 2003. Milk concentration and postnatal accretion of 429 minerals and nitrogen in two phyllostomid bats. Journal of Mammalogy 84:926-936. DOI: $430 \quad$ 10.1644/BWG-029.

431 LaDage LD, Roth II TC, Fox RA, Pravosudov V V. 2009. Effects of captivity and memory- 

based experiences on the hippocampus in mountain chickadees. Behavioral Neuroscience 123:284-291. DOI: 10.1037/a0014817.

434 Levine M, Ensom MH. 2001. Post hoc power analysis: an idea whose time has passed?

435 Pharmacotherapy 21:405-409. DOI: 10.1592/phco.21.5.405.34503.

436 Page RA, Ryan MJ. 2005. Flexibility in assessment of prey cues: frog-eating bats and frog calls. 437 Proceedings of the Royal Society Series B 272:841-847. DOI: 10.1098/rspb.2004.2998.

438 Page RA, Ryan MJ. 2006. Social transmission of novel foraging behavior in bats: frog calls and 439 their referents. Current Biology 16:1201-1205. DOI: 10.1016/j.cub.2006.04.038.

440 Page RA, Jones PL. 2016. Overcoming sensory uncertainty: factors affecting foraging decisions 441 in frog-eating bats. In: Bee MA, Miller CT, eds. Perception and Cognition in Animal $442 \quad$ Communication. New York: Springer, 285-312.

443 Park S-R. 1990. Observation on the behavioral development the common vampire bat Desmodus 444 rotundus play behaviors. Journal of the Mammalogical Society of Japan 15:25-32.

445 Patriquin KJ, Kohles JE, Page RA, Ratcliffe JM. 2018. Bats without borders: predators learn 446 novel prey cues from other predatory species. Science Advances 4:1-5. DOI:

$447 \quad 10.1126 /$ sciadv.aaq0579.

448 Piep M, Radespiel U, Zimmermann E, Schmidt S, Siemers BM. 2008. The sensory basis of prey 449 detection in captive-born grey mouse lemurs, Microcebus murinus. Animal Behaviour 450 75:871-878. DOI: 10.1016/j.anbehav.2007.07.008.

451 Ratcliffe JM, Fenton MB, Galef BG. 2003. An exception to the rule: Common vampire bats do 452 not learn taste aversions. Animal Behaviour 65:385-389. DOI: 10.1006/anbe.2003.2059.

453 Ripperger S, Günther L, Wieser H, Duda N, Hierold M, Cassens B, Kapitza R, Kölpin A, Mayer 454 F. 2019. Proximity sensors on common noctule bats reveal evidence that mothers guide 
455 juveniles to roosts but not food. Biology Letters 15: 20180884. DOI:

$456 \quad 10.1098 /$ rsbl.2018.0884.

457 Ripperger S, Josic D, Hierold M, Koelpin A, Weigel R, Hartmann M, Page R, Mayer F. 2016.

458 Automated proximity sensing in small vertebrates: design of miniaturized sensor nodes and 459 first field tests in bats. Ecology and Evolution 6:2179-2189. DOI: 10.1002/ece3.2040.

460 Rogers T, Fox S, Pemberton D, Wise P. 2016. Sympathy for the devil: captive-management style 461 did not influence survival, body-mass change or diet of Tasmanian devils 1 year after wild 462 release. Wildlife Research 43:544-552. DOI: 10.1071/WR15221.

463 Ruffell J, Parsons S. 2009. Assessment of the short-term success of a translocation of lesser 464 short-tailed bats Mystacina tuberculata. Endangered Species Research 8:33-39. DOI: $465 \quad 10.3354 /$ esr00181.

466 Schmidt U. 1988a. Orientation and sensory functions in Desmodus rotundus. In: Greenhall A, 467 Schmidt U, eds. Natural history of vampire bats. Florida: CRC Press, 143-166.

468 Schmidt C. 1988b. Reproduction. In: Greenhall A, Schmidt U, eds. Natural History of Vampire $469 \quad$ Bats. Florida, 246.

470 Schmidt U, Manske U. 1982. Thermal preference in the Common Vampire Bat Desmodus $471 \quad$ rotundus. Zeitschrift fuer Saeugetierkunde 47:118-120.

472 Schmidt U, Schlegel P, Schweizer H, Neuweiler G. 1991. Audition in vampire bats, Desmodus 473 rotundus. Journal of Comparative Physiology A 168:45-51. DOI: 10.1007/BF00217102.

474 Schuppli C, Isler K, van Schaik CP. 2012. How to explain the unusually late age at skill 475 competence among humans. Journal of Human Evolution 63:843-850. DOI: $476 \quad$ 10.1016/j.jhevol.2012.08.009.

477 Serangeli MT, Cistrone L, Ancillotto L, Tomassini A, Russo D. 2012. The post-release fate of 
hand-reared orphaned bats: Survival and habitat selection. Animal Welfare 21:9-18. DOI:

479 10.7120/096272812799129510.

480

481

482

483

484

485

486

487

488

489

490

491

492

493

494

495

496

497

498

499

500

Sikes RS, The Animal Care and Use Committee of the American Society of Mammalogists. 2016. 2016 Guidelines of the american society of mammalogists for the use of wild mammals in research and education. Journal of Mammalogy 97:663-688. DOI: 10.1093/jmammal/gyw078.

Stich KP, Winter Y. 2006. Lack of generalization of object discrimination between spatial contexts by a bat. The Journal of Experimental Biology 209:4802-4808. DOI: $10.1242 /$ jeb.02574.

Stoinski TS, Beck BB, Bloomsmith MA, Maple TL. 2003. A behavioral comparison of captiveraised, reintroduced golden lion tamarins and their wild-born offspring. Behaviour 140:134160. DOI: $10.1163 / 156853903321671479$.

Tarr BA, Rabinowitz JS, Imtiaz MA, DeVoogd TJ. 2009. Captivity reduces hippocampal volume but not survival of new cells in a food-storing bird. Developmental Neurobiology 69:972981. DOI: 10.1002/dneu.20736.

Thiele J, Winter Y. 2005. Hierarchical strategy for relocating food targets in flower bats: spatial memory versus cue-directed search. Animal Behavior 69:315-327. DOI: 10.1016/j.anbehav.2004.05.012.

Turner DC. 1975. The vampire bat: a field study in behavior and ecology. Baltimore: Johns Hopkins University Press.

Vrtilek JK, Carter GG, Patriquin KJ, Page RA, Ratcliffe JM. 2018. A method for rapid testing of social learning in vampire bats. Royal Society Open Science 5. DOI: 10.1098/rsos. 172483.

Wilkinson GS. 1984. Reciprocal food sharing in the vampire bat. Nature 308:181-184. DOI: 
$501 \quad 10.1038 / 308181 \mathrm{a} 0$.

502 Wilkinson GS. 1985. The social organization of the common vampire bat. Behavioral Ecology 503 and Sociobiology 17:123-134. DOI: 10.1007/BF00299244.

504 Wimsatt WA, Guerriere A. 1962. Observations on the feeding capacities and excretory functions 505 of captive vampire bats. Journal of Mammalogy 43:17-27.

506 Yang Z, Gu X, Nie Y, Huang F, Huang Y, Dai Q, Hu Y, Yang Y, Zhou X, Zhang H, Yang X, 507 Wei F. 2018. Reintroduction of the giant panda into the wild: A good start suggests a bright 508 future. Biological Conservation 217:181-186. DOI: 10.1016/j.biocon.2017.08.012. 


\section{Table $\mathbf{1}$ (on next page)}

Table 1. Captive born bats fed on live chicken

Categories of each type of bat that fed on live chickens. 
1

2 Table 1. Captive born bats fed on live chicken

\begin{tabular}{|l|l|l|}
\hline Category of bat & N bats & Feeding in a trial \\
\hline Wild-born, short-term captive & 3 & 2 of 3 trials when alone \\
\hline Wild-born, long-term captive & 7 & 0 of 9 trials when alone, 0 of 6 trials with offspring \\
\hline Captive-born & 12 & 5 of 12 trials when alone, 1 of 6 trials with mother \\
\hline
\end{tabular}

3 
Table 2 (on next page)

Table 2 . Feeding activity of vampire bats that did feed 
1

2 Table 2. Feeding activity of vampire bats that did feed

\begin{tabular}{|l|l|l|l|l|l|l|l|l|}
\hline Birth & $\begin{array}{l}\text { Age } \\
\text { (months) }\end{array}$ & Sex & $\begin{array}{l}\text { Body } \\
\text { mass } \\
\mathbf{( g )}\end{array}$ & $\begin{array}{l}\text { Drank } \\
\text { water }\end{array}$ & $\begin{array}{l}\text { Mass } \\
\text { change } \\
(\mathbf{g})\end{array}$ & $\begin{array}{l}\text { Mass } \\
\text { change } \\
\text { (\% mass) }\end{array}$ & $\begin{array}{l}\text { Latency } \\
\text { to feed } \\
\text { (hours) }\end{array}$ & $\begin{array}{l}\text { Time } \\
\text { active } \\
\text { (hours) }\end{array}$ \\
\hline captive & 8 & F & 32.65 & Yes & -1.08 & $-3 \%$ & 2.3 & 7.9 \\
\hline & 11 & M & 29.27 & No & -0.70 & $-2 \%$ & 3.4 & 7.3 \\
\hline & 11 & M & 24.64 & No & 0.69 & $+3 \%$ & 3.9 & 6.9 \\
\hline & $12 *$ & F & 32.04 & Yes, No & 0.51 & $+2 \%$ & 3.1 & 7.2 \\
\hline & 16 & M & 26.44 & Yes & 3.28 & $+12 \%$ & 4.0 & 6.4 \\
\hline wild & $>12$ & F & 35.07 & No & 4.21 & $+12 \%$ & 3.1 & 5.0 \\
\hline & $>12$ & M & 25.87 & Yes & 4.83 & $+19 \%$ & 1.0 & 5.6 \\
\hline
\end{tabular}

3 *bat fed once alone and once with its mother (mean of the two similar values are shown) 4 
Figure 1

Figure 1. No clear temperature preference detected in captive-born and wild-caught vampire bats.

The feeding time bias is the difference in the proportion of time spent feeding on warm blood (positive) versus cold blood (negative).

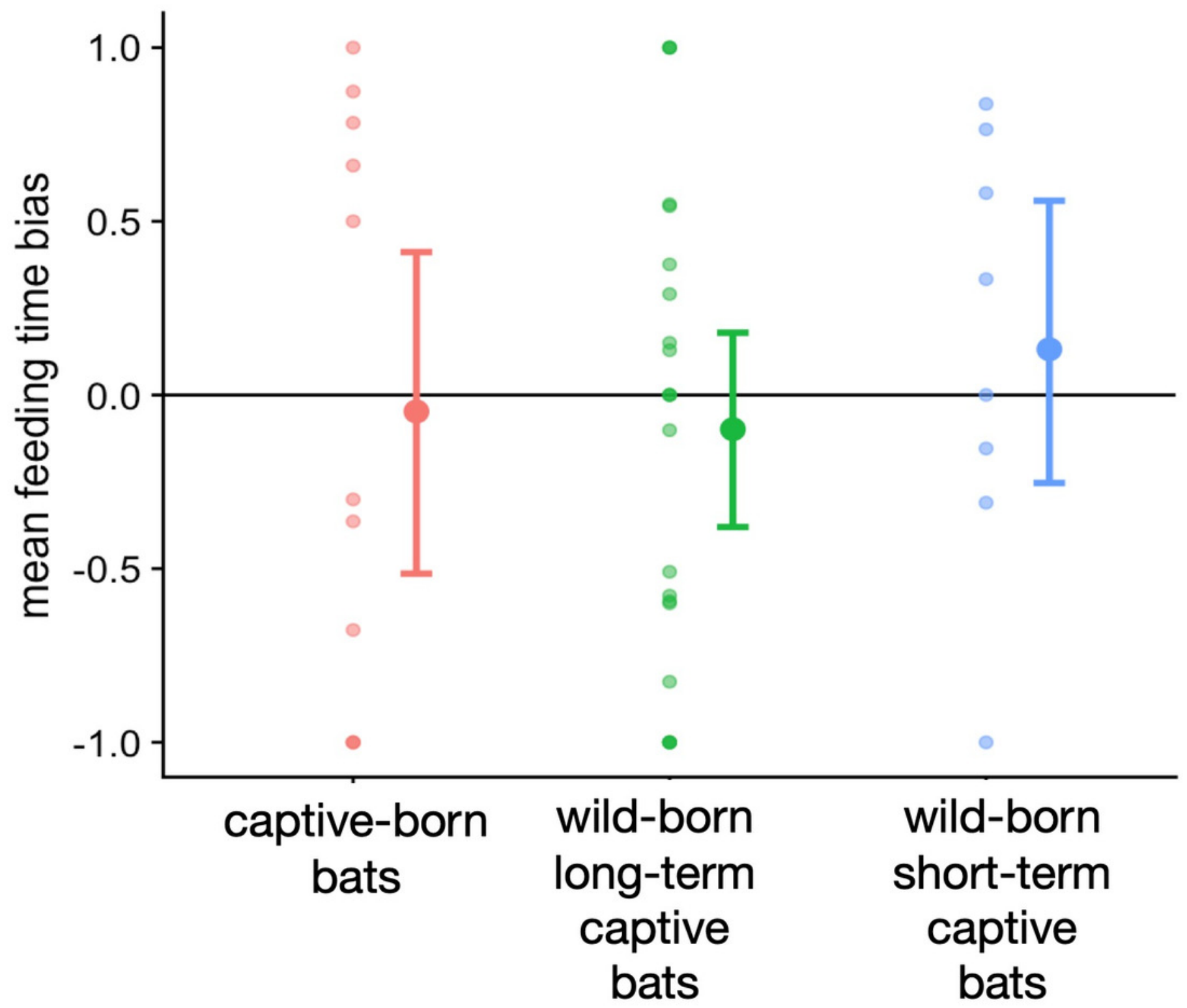

